\title{
Antitussive, anti-pyretic and toxicological evaluation of Ma-Xing-Gan-Shi-Tang in rodents
}

\author{
Yu-Chin Lin ${ }^{1}$, Ching-Wen Chang ${ }^{2,3}$ and Chi-Rei Wu ${ }^{3^{*}}$ [D
}

\begin{abstract}
Background: Ma-Xing-Gan-Shi-Tang (abbreviated as MXGST), an important Chinese herbal prescribed for cough, bronchial inflammation and fever from pneumonia, consists of four medicinal herbs, including Ephedrae herb, Semen Pruni Armeniacae, licorice and Gypsum. These components, especially Ephedrae and Semen Pruni Armeniacae, possess antitussive activities, but they have severe adverse effects.

Methods: The pharmacological activities of MXGST extract in clinical use were investigated with citric acid-induced cough, acetylcholine/histamine-induced bronchial contraction and lipopolysaccharide (LPS)-induced fever in rodents. The subacute toxicology of MXGST extract was evaluated after a 28-day repeated oral administration in rats.

Results: Each gram of MXGST extract contained $60 \pm 8 \mu \mathrm{g}$ of ephedrine, $480 \pm 40 \mu \mathrm{g}$ of glycyrrhizic acid and $440 \pm 8 \mu \mathrm{g}$ of amygdalin according to high performance liquid chromatography and a photodiode array detector. MXGST extract produced pronounced, dose-dependent antitussive effects in guinea pigs and reduced hyperthermic syndrome induced by LPS in rats. MXGST extract blocked the bronchial contraction induced by acetylcholine/histamine. Oral administration of MXGST extract for 28 days did not cause any hematological, biochemical or histological changes in rats.

Conclusions: MXGST extract is a safer, more effective Chinese prescription with antitussive and anti-pyretic effects. The antitussive mechanism of MXGST is related to partially relaxing the bronchial smooth muscle by blocking acetylcholinergic and histaminergic receptors.
\end{abstract}

Keywords: Ma-Xing-Gan-Shi-Tang, Antitussive, Anti-pyretic effects, Subacute toxicology test

\section{Background}

Cough is a beneficial, important protective reflex against irritants or foreign materials, and coughing helps keep the respiratory tract clear. However, cough is a primary symptom of respiratory illness with a high worldwide incidence. It is not only a common symptom of lung diseases, such as upper respiratory tract infection, it is one of the most common complaints that diminishes the patient's comfort and causes sleep disturbances $[1,2]$. Based on the physiological mechanism of the medulla oblongata controlling the coughing reflex, centrally acting antitussive drugs, such as

\footnotetext{
* Correspondence: crw@mail.cmu.edu.tw

${ }^{3}$ Department of Chinese Pharmaceutical Sciences and Chinese Medicine Resources, China Medical University, No. 91, Hsieh Shih Road, Taichung 40402, Taiwan, ROC

Full list of author information is available at the end of the article
}

codeine and dextromethorphan, were developed, but their clinic utility has been limited by their undesirable and intolerable side effects such as sedation, nausea, addictive potential and constipation [3, 4]. Therefore, the discovery of novel, safe and effective antitussive agents for treating cough could be facilitated by investigating medicinal plants or herb prescriptions. Ma-Xing-Gan-Shi-Tang (abbreviated as MXGST), an important Chinese herbal medicine for treating cough and fever from pneumonia, consists of Ephedrae (the stem of Ephedra intermedia), Semen Pruni Armeniacae (the semen of Prunus armeniaca), licorice (the roots of Glycyrrhiza uralensis), and Gypsum [5]. Pharmacological reports have indicated that MXGST possesses antiasthmatic and anti-pyretic activities in allergy-induced or ovalbumin-induced rodent bronchial inflammation models 
and a rabbit fever model [6-10]. Its major component, Ephedrae, a plant containing multiple active alkaloids, possesses antitussive and anti-asthmatic activities and has been used to treat upper respiratory tract infection or asthma for decades. However, Ephedrae prescriptions are restricted by the US Food and Drug Administration due to their cardiovascular and CNS stimulatory adverse effects, which result from its principal alkaloid ephedrine, a sympathomimetic agonist at $\alpha$ - and $\beta$-adrenergic receptors $[11,12]$. The second important component Semen Pruni Armeniacae also possesses antitussive activities via its major ingredient amygdalin which biotransformed into cyanide. However, the therapeutic index of cyanide is very narrow and cyanide intoxication can occur $[13,14]$. Therefore, the present study attempted to investigate the antitussive and anti-pyretic effects of MXGST extract in rodents with citric acid-induced cough [15] and lipopolysaccharide (LPS)-induced hyperthermia [16]. Then, we further investigated the antitussive mechanism of MXGST extract using acetylcholine/histamine-induced bronchial contraction in guinea pigs. Furthermore, we performed a 28-day repeated oral subacute toxicology test of MXGST extract because the major components of MXGST extract, including Ephedrae, Semen Pruni Armeniacae and licorice have toxicological reports in animal and clinical application [11-14, 17-20].

\section{Methods}

\section{Preparation of plant extract}

Ephedrae (TWU-Plantec-MXGST-0001), Semen Pruni Armeniacae (TWU-Plantec-MXGST-0002), licorice (TWU-Plantec-MXGST-0003) and Gypsum (TWUPlantec-MXGST-0004) were purchased from the Taiwan market and identified by Professor Lin Y. C. using macroscopic and microscopic methods. These medicinal materials were deposited in the Department of Medicinal Botanicals and Health Applications, DaYeh University. MXGST $(8.5 \mathrm{~kg})$ consisted of the aforementioned medicinal materials at a ratio of $4: 3: 2: 8$. They were cut into thin slices and place into a container $\left(100 \times 100 \times 100 \mathrm{~cm}^{3}\right)$. Then, distilled water was added and heated at $100{ }^{\circ} \mathrm{C}$ for $60 \mathrm{~min}$. The solution was concentrated and dried with a rotary evaporator (Laborota 20 compact, Heidolph Instruments $\mathrm{GmbH} \&$ Co. (Schwabach, Germany)) at $50{ }^{\circ} \mathrm{C}$ and 120-180 mbar. MXGST extract (459 g, 5.4 \% yield) was ground into powder, and sealed in a Pyrex glass bottle. The ephedrine, glycyrrhizic acid and amygdalin levels in MXGST extract were approximately $60 \pm 8$, $480 \pm 40$ and $440 \pm 8 \mu \mathrm{g} / \mathrm{g}$ dry weight, which is in accordance with the calibration curve of ephedrine, glycyrrhizic acid and amygdalin determined by high performance liquid chromatography and a photodiode array detector at 254 and $214 \mathrm{~nm}$. The validation parameters of ephedrine, glycyrrhizic acid and amygdalin are shown in Table 1.

MXGST extract $(0.2,0.4,1.0$ and $2.0 \mathrm{~g} / \mathrm{kg})$ was dissolved in sterile distilled water and administered orally $120 \mathrm{~min}$ prior to the injection of an inducer. The control was treated with sterile distilled water in the same experiments. Aminophylline (125 mg/kg) was prepared as a suspension with $0.5 \%$ carboxymethylcellulose and administered orally $30 \mathrm{~min}$ prior to the injection of an inducer.

\section{Animals}

Male Sprague-Dawley rats (200-250 g) were used in an LPS-induced hyperthermic test and 28-day repeated oral subacute toxicity test. Male guinea pigs (150-200 g) were used in citric acid-induced cough test. The experimental protocol (Protocol No. 102103-NH) was approved by the Institutional Animal Care and Use Committee (IACUC) of China Medical University and animal care was performed according to the Guiding Principles for the Care and Use of Laboratory Animals. The animals were housed for at least 1 week before starting the experiment in a temperature- $\left(23 \pm 1{ }^{\circ} \mathrm{C}\right)$ and humidity- $(60 \%)$ regulated environment; they had with free access to standard food in pellets and tap water on a 12-12 h light/dark cycle (light phase: 08:00-20:00 h). After 1 week of acclimatization, eight rodents in each group of the below experiments were used. Then, the drugs were administered and antitussive and anti-pyretic assays were performed using a double-blind method. After behavioral measurement, all animals were killed with carbon dioxide.

\section{Citric acid-induced cough in guinea pigs}

Cough was induced by inhalation of $17.5 \%$ citric acid aerosol, which has been shown to induce the cough reflex in guinea pigs [15]. The aerosol was administered to animals via a small-volume ultrasonic nebulizer that was connected to the bias flow port immediately before the exposure chamber inlet. A

Table 1 Validation parameters for ephedrine, glycyrrhizic acid and amygdalin by high performance liquid chromatography

\begin{tabular}{llllll}
\hline Compound & Concentration range $(\mu \mathrm{g} / \mathrm{mL})$ & $\mathrm{R}^{2}$ & Linear regression & Intra-D (\%) & Inter-D (\%) \\
\hline Ephedrine & $6.25-100$ & 0.997 & $\mathrm{Y}=0.454 x-0.0356$ & $1.00-2.74$ & $0.98-3.02$ \\
Glycyrrhizic acid & $6.25-100$ & 0.999 & $\mathrm{Y}=0.052 x+0.0046$ & $0.34-3.76$ & $0.62-2.84$ \\
Amygdalin & $6.25-100$ & 0.990 & $\mathrm{Y}=0.0645 \mathrm{x}+0.0788$ & $1.61-4.33$ & $1.48-3.67$ \\
\hline
\end{tabular}


volume of $5 \mathrm{~mL}$ of citric acid solution was placed into the ultrasonic nebulizer. During the 5-min aerosolization period, approximately $0.4 \mathrm{~mL}$ of the solution was nebulized. The onset and frequency of cough during 15 min (aerosolization time + observation time) were recorded.

\section{Acetylcholine/histamine-induced bronchial contraction in guinea pigs}

To explore the antitussive mechanism of MXGST extract, guinea pigs were placed in a glass chamber ( $3 \mathrm{~L}$ volume) and sprayed with a mixture of $0.1 \%$ histamine and $2 \%$ acetylcholine chloride $(1: 1, \mathrm{v} / \mathrm{v})$ for $15 \mathrm{~s}$. The onset of respiratory distress and tumble (pre-convulsive time) were recorded. The guinea pigs with a pre-convulsive time of more than $120 \mathrm{~s}$ were considered insensitive and were discarded. The eligible guinea pigs were randomly divided into five groups, normal, three doses of MXGST extract (0.2, 0.4 and $1.0 \mathrm{~g} / \mathrm{kg})$ and aminophylline $(125 \mathrm{mg} / \mathrm{kg})$. The preconvulsive times for each guinea pig within 6 min were observed.

\section{LPS-induced hyperthermia in rats}

The anti-pyretic activity of MXGST extract was evaluated against LPS-induced hyperthermia in rats [16]. Fever was induced by intraperitoneal injection of $10 \mathrm{~mL} / \mathrm{kg}$ of $100 \mu \mathrm{g} / \mathrm{kg}$ LPS. The rectal temperature was recorded using clinical thermometer immediately before MXGST treatment and immediately before and 1-6 $\mathrm{h}$ after LPS injection. Prior to the experiment, the rats were maintained in separate cages for 7 days and the animals with an approximately constant rectal temperature were selected for the study.

\section{Subacute toxicity study in the rats}

The 28-day repeated oral toxicity studies were performed in rats according to the OECD test guideline 407 [21]. Rats were randomly divided into 4 groups of 8 animals each. After an overnight fast, group 1 received sterile distilled water, while groups $2-4$ included rats that received MXGST extract at doses of $0.4, \quad 1.0$ and $2.0 \mathrm{~g} / \mathrm{kg}$ body weight, respectively. MXGST extract were administered daily by oral gavage in the volume of $10 \mathrm{~mL} / \mathrm{kg}$ body weight, once daily for 28 days. The rats were observed daily for any abnormal clinical signs and death during the study period. Body weight and food intake were measured and recorded daily during the study period. At the end of the study, all animals were fasted overnight. The animals were weighed. Blood was collected using the retro-orbital technique with or without ethylenediaminetetraacetic acid (EDTA) for hematological and biochemical analyses, respectively. The animals were sacrificed and body organs, including the lung, liver and kidney, were removed for detailed weight and histopathological changes.

\section{Hematological parameters and biochemical estimations}

Red blood cells (RBCs), white blood cells (WBCs), hematocrit (HCT), hemoglobin (HGB), mean corpuscular hemoglobin $(\mathrm{MCH})$, mean corpuscular hemoglobin concentration (MCHC), mean corpuscular volume (MCV) and platelet counts [22] were determined in control and MXGST extract-treated groups. The serum was carefully aspirated into sample bottles for various biochemical assays. Aspartate transaminase (AST), alanine transaminase (ALT), creatinine, blood glucose, blood urea nitrogen (BUN), total protein and albumin analyses were determined using Radox diagnostic assay kits.

\section{Organs weight and histology}

The rats were quickly dissected and major organs, including the brain, heart, lung, liver, spleen, kidney, adrenal and testis were excised and weighed. The specimens for histopathology were fixed in $10 \%$ neutral, buffered formalin for $18 \mathrm{~h}$ at $4{ }^{\circ} \mathrm{C}$. The thickness $(4 \mu \mathrm{m})$ of each lung, liver and kidney specimen was cut and stained with hematoxylin and eosin stain according to standard laboratory procedures. The stained sections were examined under a microscope for any cellular damage or change in tissue morphology.

\section{Statistical analysis}

All data obtained during antitussive and anti-pyretic activity were expressed in terms of the mean and standard errors, and further analyzed using ANOVA one-way analysis of variance, which was followed by Scheff's test. When the probability $(p)$ was less than 0.05 , the difference was considered to be significant.

\section{Results \\ Effects of MXGST extract on citric acid-induced cough in guinea pigs}

The onset time for citric acid-induced cough in normal animals ranged from 26.9 to $62.4 \mathrm{~s}$, averaging $48.7 \mathrm{~s}$. The cough incidence in normal animals ranged from 24 to 35 coughs, averaging 29.0. The averaging onset time for citric acid-induced cough in guinea pig treated with MXGST at $0.2,0.4$ and $1.0 \mathrm{~g} / \mathrm{kg}$ was $49.8,68.8$ and $107.7 \mathrm{~s}$, respectively. The averaging cough frequency in guinea pig treated with MXGST at 0.2, 0.4 and $1.0 \mathrm{~g} / \mathrm{kg}$ was 29.5, 21.0 and 13.3, respectively. Hence, MXGST extract at $0.4-1.0 \mathrm{~g} / \mathrm{kg}$ decreased the citric acidinduced cough frequency in a dose-dependent manner (Fig. 1(b); $p<0.01, p<0.001$ ), but only at $1.0 \mathrm{~g} / \mathrm{kg}$ delayed the onset time for citric acid-induced cough (Fig. 1(a); $p<0.001)$. Aminophylline, a positive control, 

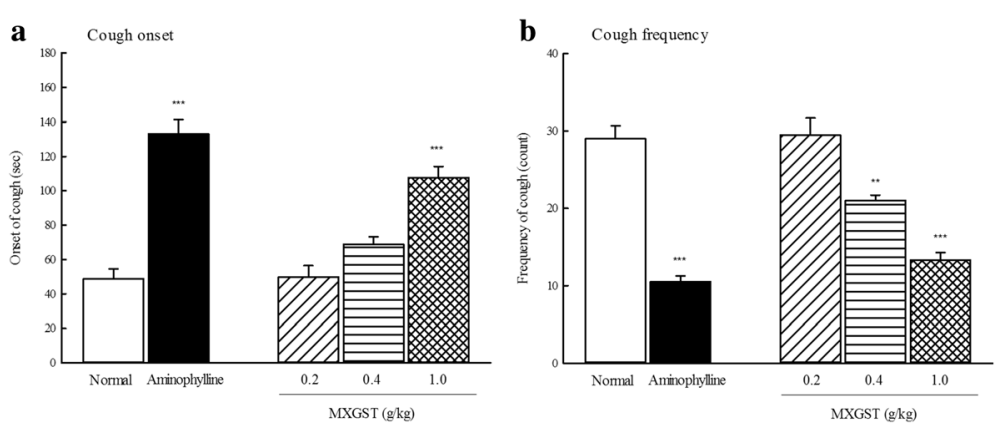

Fig. 1 Effect of Ma-Xing-Gan-Shi-Tang (MXGST, 0.2, $0.4,1.0 \mathrm{~g} / \mathrm{kg}$, po) and aminophylline (125 mg/kg, po) on (a) the onset time and (b) the frequency of citric acid-induced cough response in guinea pig. Each values are represented as mean \pm S.E. $(N=6)$. ${ }^{* *} p<0.01,{ }^{* * *} p<0.001$ as compared with the normal group

at $125 \mathrm{mg} / \mathrm{kg}$, also decreased the citric acid-induced cough frequency and delayed the onset time for citric acid-induced cough (Fig. $1 ; p<0.001$ ).

Effects of MXGST extract on the acetylcholine/histamineinduced bronchial contraction in guinea pigs

The pre-convulsive time of acetylcholine/histamine induced tracheobronchial tonic contraction in guinea pigs ranged from 48.9 to $89.0 \mathrm{~s}$, averaging $59.3 \mathrm{~s}$. The averaging pre-convulsive time of acetylcholine/histamine induced tracheobronchial tonic contraction in guinea pig treated with MXGST at $0.2,0.4$ and $1.0 \mathrm{~g} / \mathrm{kg}$ was 64.6, 88.5 and $127.6 \mathrm{~s}$, respectively. Hence, MXGST extract (only at $1.0 \mathrm{~g} / \mathrm{kg}$ ) and aminophylline $(125 \mathrm{mg} / \mathrm{kg}$ ) delayed the pre-convulsive time of acetylcholine/histamine induced tracheobronchial tonic contraction (Fig. 2; $p<0.01, p<0.001)$.

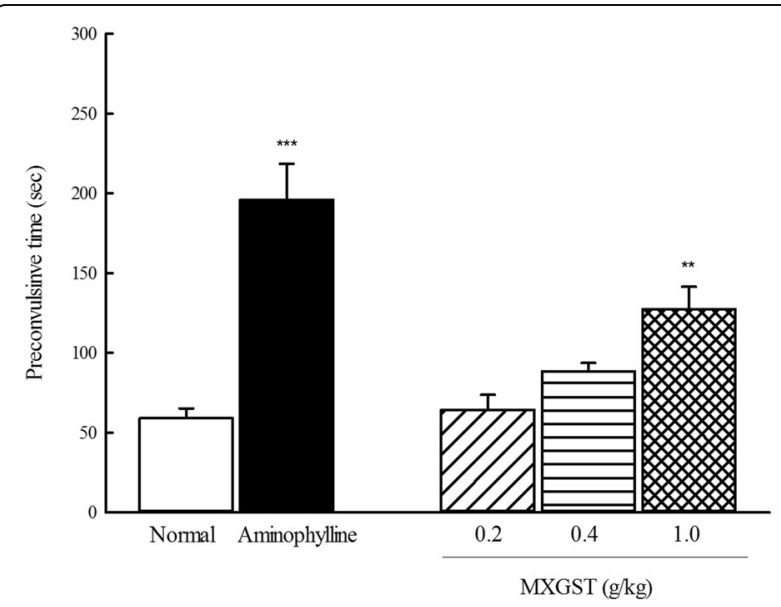

Fig. 2 Effect of Ma-Xing-Gan-Shi-Tang (MXGST, 0.2, 0.4, $1.0 \mathrm{~g} / \mathrm{kg}$, po) and aminophylline $(125 \mathrm{mg} / \mathrm{kg}$, po) on the pre-convulsive time of acetylcholine/serotonin-induced tracheobronchial tonic contraction in guinea pig. Each values are represented as mean \pm S.E. $(N=6)$. ** $p<0.01,{ }^{* * *} p<0.001$ as compared with the normal group
Effects of MXGST extract on LPS-induced hyperthermia in rats

The rectal temperature of normal rats maintained at $35.8-36.1{ }^{\circ} \mathrm{C}$. The rectal temperature of LPS-induced rats was gradually raised from 35.9 to $37.4{ }^{\circ} \mathrm{C}$, and then maintained at $37.1{ }^{\circ} \mathrm{C}$ from 4 to $6 \mathrm{~h}$ after LPS injection. So, the rats showed a stable increase in the rectal temperature immediately after LPS injection and reached a plateau period in which their rectal temperature increased approximately $1.5{ }^{\circ} \mathrm{C}$ on average, $3 \mathrm{~h}$ after LPS injection (Fig. $3 ; p<0.001$ ). The tendency of rectal temperature raised by LPS in rats treated with MXGST at $0.2 \mathrm{~g} / \mathrm{kg}$ was similar to that in LPS-induced rats, and finally their rectal temperature maintained at $37.0{ }^{\circ} \mathrm{C}$. Treatment with MXGST at $0.4 \mathrm{~g} / \mathrm{kg}$, their rectal temperature was raised to $36.5^{\circ} \mathrm{C}$ $1 \mathrm{~h}$ after LPS injection, and then maintained at 36.2$36.5{ }^{\circ} \mathrm{C}$. Treatment with MXGST at $1.0 \mathrm{~g} / \mathrm{kg}$, their rectal temperature was raised to $36.3{ }^{\circ} \mathrm{C} 1 \mathrm{~h}$ after LPS injection, and then maintained at $35.9-36.1{ }^{\circ} \mathrm{C}$. Hence,

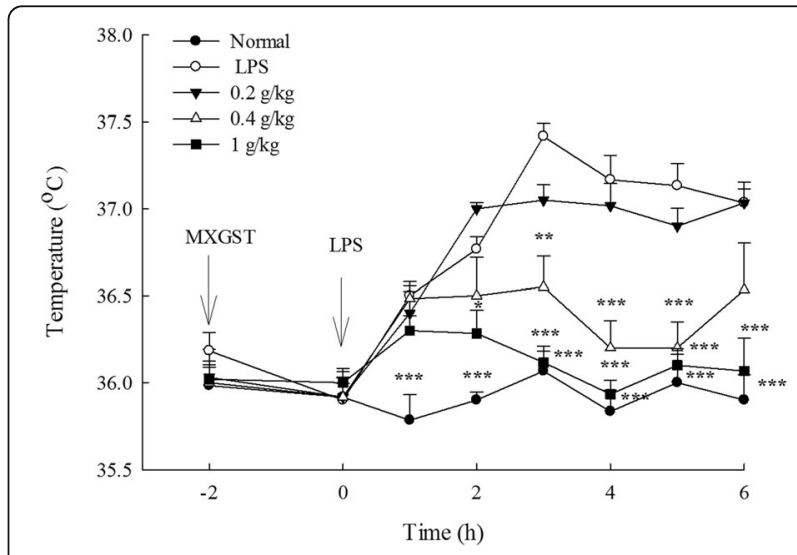

Fig. 3 Effect of Ma-Xing-Gan-Shi-Tang (MXGST, 0.2, 0.4, $1.0 \mathrm{~g} / \mathrm{kg}$, po) on the lipopolysaccharide (LPS, $100 \mu \mathrm{g} / \mathrm{kg}$, ip)-induced hyperthermia in rats. Each values are represented as mean \pm S.E. $(N=6) .{ }^{*} p<0.05$, ${ }^{* *} p<0.01,{ }^{* * *} p<0.001$, as compared with the LPS group 

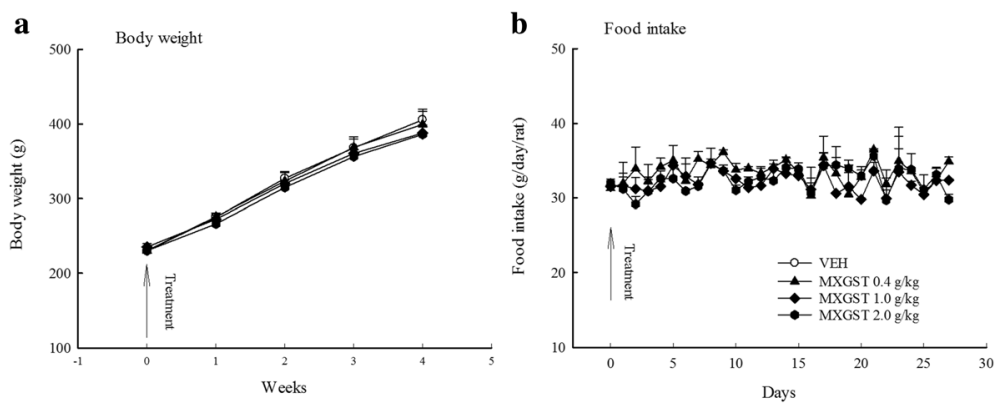

Fig. 4 Effect of Ma-Xing-Gan-Shi-Tang (MXGST, 0.4, 1.0, $2.0 \mathrm{~g} / \mathrm{kg}$, po) on (a) the tendency of body weight and (b) daily food intake during 28-day repeated treatment in rats. Each value are represented as mean \pm S.E. $(N=6)$

MXGST extract, at 0.4 and $1.0 \mathrm{~g} / \mathrm{kg}$, produced significant anti-pyretic activity from 2 to $6 \mathrm{~h}$ after LPS injection in a dose-dependent manner (Fig. 3; $p<0.05$ and $p<0.01)$.

\section{Sub-acute toxicology of MXGST extract}

Average body weight of all rats before any treatment was $230 \mathrm{gm}$. After eight treatment with vehicle, 0.4, 1.0 or $2.0 \mathrm{~g} / \mathrm{kg}$ of MXGST, their average body weight of each group was $405.8 \pm 14.6,399.8 \pm 17.7,388.0 \pm$ 9.6 , and $386.2 \pm 12.7 \mathrm{gm}$, respectively. Oral treatment with MXGST extract at 1.0 or $2.0 \mathrm{~g} / \mathrm{kg}$ for 28 -days caused a slight tendency in body weight loss in a dosedependent manner, but this was not significant compared with the control group (Fig. 4(a) and (b)). Again, there were no significant difference in the hematological parameters including RBC, HGB, HCT, $\mathrm{MCV}, \mathrm{MCH}, \mathrm{MCHC}, \mathrm{WBC}$ and platelet counts between rats treated with MXGST extract $(0.4,1.0$ or $2.0 \mathrm{~g} / \mathrm{kg}$ ) or vehicle (Table $2, p>0.05$ ). The biochemical parameters for liver and kidney function tests, such as AST, ALT, creatinine, BUN, blood glucose, total protein and albumin, of rats treated with MXGST extract $(0.4,1.0$ or $2.0 \mathrm{~g} / \mathrm{kg})$ were not significantly different from those of the control group (Table $3, p>0.05$ ). The urine parameters, including the volume, $\mathrm{pH}$ value, protein and glucose, of rats treated with MXGST extract at $0.4,1.0$ or $2.0 \mathrm{~g} / \mathrm{kg}$ were not significantly different from those of the control group (Table $4, p>0.05$ ). Finally, there were no significant difference between rats treated with MXGST extract $(0.4,1.0$ or $2.0 \mathrm{~g} / \mathrm{kg})$ or vehicle in their mean weights and gross examinations of major organs, including the brain, heart, lungs, liver, spleen, kidneys, adrenal glands and testis dissected from all rats (Table 5, $p>0.05$ ). When MXGST was administered at a higher dose $(2.0 \mathrm{~g} / \mathrm{kg})$ for 28 days, no histopathological changes in the lungs, liver or kidneys were observed (Fig. 5).

\section{Discussion}

MXGST is mainly used by traditional Chinese physicians to treat cough from pneumonia. A recent report indicated that MXGST prolonged the coughing onset and decreased the coughing frequency of ammoniainduced cough in rats [23]. Citric acid-induced cough is a very useful model for assessing the antitussive effects of medicinal plants and synthetic compounds. Hence, we first performed a citric acid-induced cough to evaluate the antitussive effects of MXGST extract in guinea pigs. The dosage $(0.4 \mathrm{~g} / \mathrm{kg})$ of MXGST was chosen according to the conversion of the clinical daily therapeutic dosage [5] to animal equivalent dosage by body surface area and other reports $[6,7,23]$. The present data are similar to the effects of MXGST on ammonia-induced cough [23], indicating that

Table 2 Effects of Ma-Xing-Gan-Shi-Tang (MXGST, 0.4, 1.0, $2.0 \mathrm{~g} / \mathrm{kg}, \mathrm{po}$ ) after 28-day repeated oral administration on hematological parameters in rats

\begin{tabular}{|c|c|c|c|c|c|c|c|c|}
\hline Groups & RBC (10 cells/ $\mu \mathrm{L})$ & HGB (g/dL) & MCV (fj) & $\mathrm{MCH}(\mathrm{pg})$ & $\mathrm{MCHC}(\mathrm{g} / \mathrm{dL})$ & HCT (\%) & WBC $\left(10^{3}\right.$ cells/uL) & Platelet ( $10^{3}$ cells $\left./ \mu \mathrm{L}\right)$ \\
\hline Normal & $7.1 \pm 0.3$ & $14.7 \pm 0.4$ & $59.0 \pm 0.8$ & $20.9 \pm 0.4$ & $35.5 \pm 0.8$ & $41.5 \pm 1.5$ & $8.9 \pm 1.2$ & $784.5 \pm 68.6$ \\
\hline MXGST 0.4 g/kg & $7.0 \pm 0.1$ & $15.1 \pm 0.2$ & $59.3 \pm 1.3$ & $21.6 \pm 0.3$ & $36.5 \pm 0.6$ & $41.6 \pm 1.1$ & $9.2 \pm 1.5$ & $816.2 \pm 42.3$ \\
\hline MXGST $1.0 \mathrm{~g} / \mathrm{kg}$ & $6.8 \pm 0.1$ & $14.7 \pm 0.2$ & $58.0 \pm 1.1$ & $21.6 \pm 0.3$ & $37.3 \pm 0.5$ & $39.5 \pm 1.0$ & $8.0 \pm 1.0$ & $839.7 \pm 36.8$ \\
\hline MXGST $2.0 \mathrm{~g} / \mathrm{kg}$ & $7.3 \pm 0.2$ & $15.6 \pm 0.3$ & $58.7 \pm 1.2$ & $21.5 \pm 0.3$ & $36.7 \pm 0.5$ & $42.6 \pm 1.2$ & $10.9 \pm 1.2$ & $936.2 \pm 55.9$ \\
\hline
\end{tabular}

Data are represented with mean $\pm \mathrm{SEM}, N=6$ 
Table 3 Effects of Ma-Xing-Gan-Shi-Tang (MXGST, 0.4, 1.0, $2.0 \mathrm{~g} / \mathrm{kg}, \mathrm{po})$ after 28-day repeated oral administration on plasma biochemical parameters in rats

\begin{tabular}{lccccccc}
\hline Groups & Glu $(\mathrm{mg} / \mathrm{dL})$ & TP $(\mathrm{mg} / \mathrm{dL})$ & Albumin $(\mathrm{mg} / \mathrm{dL})$ & ALT $(\mathrm{U} / \mathrm{L})$ & AST $(\mathrm{U} / \mathrm{L})$ & BUN $(\mathrm{mg} / \mathrm{dL})$ & Creatinine $(\mathrm{mg} / \mathrm{dL})$ \\
\hline Normal & $173.8 \pm 12.9$ & $5.8 \pm 0.4$ & $3.9 \pm 0.1$ & $74.1 \pm 3.8$ & $73.7 \pm 2.7$ & $25.2 \pm 2.4$ & $0.29 \pm 0.02$ \\
MXGST 0.4 g/kg & $188.2 \pm 3.0$ & $6.2 \pm 0.1$ & $3.9 \pm 0.1$ & $70.8 \pm 5.2$ & $69.3 \pm 1.5$ & $27.0 \pm 2.4$ & $0.31 \pm 0.02$ \\
MXGST 1.0 g/kg & $185.2 \pm 5.4$ & $5.9 \pm 0.1$ & $3.8 \pm 0.1$ & $65.3 \pm 4.0$ & $78.5 \pm 6.5$ & $25.3 \pm 2.4$ & $0.28 \pm 0.02$ \\
MXGST 2.0 g/kg & $193.0 \pm 7.1$ & $6.1 \pm 0.2$ & $4.0 \pm 0.1$ & $58.5 \pm 2.4$ & $71.1 \pm 2.2$ & $21.5 \pm 1.1$ & $0.30 \pm 0.02$ \\
\hline
\end{tabular}

Data are represented with mean $\pm \mathrm{SEM}, \mathrm{N}=6$

MXGST and the aminophylline positive control had antitussive effects on the citric acid-induced cough model. Furthermore, citric acid stimulated rapidly adapting, histaminergic and acetylcholinergic receptors that are located in the larynx and upper airways of the tracheobronchial tree by opening the $\mathrm{pH}$ gated ion channels to induce cough and tracheobronchial contraction [2]. The inhalation of citric acid also causes bronchial hyperresponsiveness to acetylcholine and hypersensitivity to histamine-induced microvascular leakage, which can then induce tracheobronchial contraction and cough [2]. As a result, the antitussive mechanism of MXGST extract on the bronchial tract was explored by acetylcholine/histamine-induced tracheobronchial contraction in guinea pigs. We also found that MXGST and positive control aminophylline relaxed the tracheobronchial contraction caused by acetylcholine/histamine. Another researcher indicated that MXGST relieved airway resistance increases by Dermatophagoides Pteronyssinus in guinea pigs [7]. Moreover, Ephedrae possessed the antitussive effects of citric acid-induced cough in guinea pigs [24]. Additionally, ephedrine and methylephedrine (both active ingredients of Ephedrae) have antitussive and antiasthmatic effects in animal models and humans. They can dilate bronchial smooth muscle via activating both sympathomimetic $\alpha$ - and $\beta$-adrenergic receptors [25, 26]. Amygdalin, a major constituent of Semen Pruni Armeniacae, also possesses antitussive activities via inhibiting the central cough center when it is biotransformed into cyanide, an active ingredient [25]. Licorice also decreased the cough response induced by

Table 4 Effects of Ma-Xing-Gan-Shi-Tang (MXGST, 0.4, 1.0, $2.0 \mathrm{~g} / \mathrm{kg}$, po) after 28-day repeated oral administration on urine parameters in rats

\begin{tabular}{lcclc}
\hline Groups & Volumes $(\mathrm{mL})$ & $\mathrm{pH}$ value & $\begin{array}{l}\text { Protein } \\
(\mathrm{mg} / \mathrm{L})\end{array}$ & $\begin{array}{l}\text { Glucose } \\
(\mathrm{mmol} / \mathrm{L})\end{array}$ \\
\hline Normal & $22.0 \pm 1.9$ & $7.2 \pm 0.1$ & $37.1 \pm 2.3$ & $6.9 \pm 0.8$ \\
MXGST $0.4 \mathrm{~g} / \mathrm{kg}$ & $21.8 \pm 2.3$ & $7.1 \pm 0.2$ & $38.5 \pm 2.9$ & $6.8 \pm 0.7$ \\
MXGST $1.0 \mathrm{~g} / \mathrm{kg}$ & $21.7 \pm 3.3$ & $6.9 \pm 0.3$ & $44.0 \pm 4.7$ & $6.7 \pm 1.5$ \\
MXGST $2.0 \mathrm{~g} / \mathrm{kg}$ & $20.2 \pm 3.3$ & $6.8 \pm 0.1$ & $39.5 \pm 2.7$ & $6.8 \pm 0.8$ \\
\hline
\end{tabular}

Data are represented with mean \pm SEM, $N=6$ ammonia or capsaicin [27, 28]. Moreover, cotreatment with Ephedrae and Semen Pruni Armeniacae has better antitussive effects than Ephedrae or Semen Pruni Armeniacae alone [9]. Thus, we suggested that MXGST extract, at a lower dosage than the reported dosage of each medicinal component, possessed antitussive effects. These effects might be due to the synergic effects of its medicinal components, especially of Ephedrae and Semen Pruni Armeniacae [9]. The antitussive mechanism of MXGST might be related to dilating the bronchial smooth muscle by inhibiting the histaminergic and acetylcholinergic receptors in the bronchial tract, activating both sympathomimetic $\alpha$ - and $\beta$-adrenergic receptors from ephedra alkaloids and inhibiting the central cough center from amygdalin $[25,26]$. However, citric acidinduced cough and tracheobronchial constriction are partially mediated by the nonadrenergic-noncholinergic-nonhistaminergic nervous systems, which include tachykinins, leukotrienes and prostaglandin $E_{2}$ from mast cells [29-33]. Therefore, whether the antitussive mechanism of MXGST might be related to stabilizing mast cells and inhibiting other inflammatory mediators and nervous systems must be investigated in the future.

Second, the anti-pyretic effects of MXGST extract on LPS-induced hyperthermia in rats were evaluated because traditional Chinese physicians mainly use MXGST to treat fever caused by pneumonia. This result is consistent with other report that MXGST possesses anti-pyretic effects on a typhoid/paratyphoid vaccine-induced fever model in rabbits [6]. Some researchers indicated that Gypsum possesses anti-pyretic effects in Brewer's yeast-induced hyperthermia via decreasing the hypothalamus prostaglandin $E_{2}$ levels [34]. Glycyrrhetic acid, a major ingredient of licorice, possesses anti-pyretic effects in Brewer's yeast-induced fever in rats via the pituitary adrenal axis [35]. The herb pairs, Ephedrae and Gypsum, significantly attenuated Brewer's yeast-induced fever in rats [36]. Therefore, it can be suggested that MXGST possesses anti-pyretic effects via the synergic effects of its medicinal components, especially Gypsum and Ephedrae [8, 36], and this effect might be mediated through the modulation of 
Table 5 Effects of Ma-Xing-Gan-Shi-Tang (MXGST, 0.4, 1.0, $2.0 \mathrm{~g} / \mathrm{kg}, \mathrm{po}$ ) after 28-day repeated oral administration on organ weight in rats

\begin{tabular}{llllllll}
\hline Groups & Brain $(\mathrm{g})$ & Heart $(\mathrm{g})$ & Lung $(\mathrm{g})$ & Liver $(\mathrm{g})$ & Spleen $(\mathrm{g})$ & Kidney $(\mathrm{g})$ & Adrenal $(\mathrm{mg})$ \\
\hline Normal & $1.97 \pm 0.05$ & $1.37 \pm 0.04$ & $1.38 \pm 0.09$ & $15.71 \pm 0.56$ & $0.80 \pm 0.07$ & $2.71 \pm 0.09$ & $61 \pm 2$ \\
MXGST 0.4 g/kg & $1.98 \pm 0.03$ & $1.39 \pm 0.06$ & $1.45 \pm 0.04$ & $15.49 \pm 0.71$ & $0.97 \pm 0.11$ & $2.73 \pm 0.10$ & $59 \pm 2$ \\
MXGST 1.0 g/kg & $1.99 \pm 0.04$ & $1.26 \pm 0.05$ & $1.34 \pm 0.02$ & $14.56 \pm 0.43$ & $0.81 \pm 0.04$ & $2.57 \pm 0.03$ & $57 \pm 3$ \\
MXGST 2.0 g/kg & $2.07 \pm 0.04$ & $1.33 \pm 0.08$ & $1.44 \pm 0.08$ & $15.06 \pm 0.69$ & $0.92 \pm 0.09$ & $2.57 \pm 0.11$ & $60 \pm 4$ \\
\hline
\end{tabular}

Data are represented with mean $\pm \mathrm{SEM}, \mathrm{N}=6$

prostaglandin $E_{2}$ synthesis in the hypothalamus adrenal gland axis from glycyrrhizic acid and Gypsum [34, 35].

Each MXGST component has been reported to have the various adverse effects, such as cardiovascular and CNS toxicology of Ephedra [11, 12, 18, 19], edema and mineralocorticoid excess syndrome of licorice [20], cyanide toxic reaction of Semen Pruni Armeniacae [13, 14, 17], and allergic response of Gypsum [37]. Therefore, we further evaluated the subacute toxicology of MXGST at $0.4,1.0$ or $2.0 \mathrm{~g} / \mathrm{kg}$ after 28-day repeated oral administration in rats because MXGST possesses antitussive and anti-pyretic effects at doses of $0.4-1.0 \mathrm{~g} / \mathrm{kg}$. Rats treated with MXGST extract at $0.4,1.0$ or $2.0 \mathrm{~g} / \mathrm{kg}$ body weight daily for 28 days survived throughout the period and did not show any changes in their general behavior or other physiological activities. We also found that oral administration of the MXGST extract at 5 times the effective dose for 28 days did not cause any toxicological responses or histopathological changes, and then MXGST which consists of Ephedrae, Semen Pruni Armeniacae, licorice and Gypsum did not show any toxicities such as cardiovascular and CNS toxicology from Ephedra [11, 12, 18, 19], mineralocorticoid excess syndrome from licorice [20], cyanide toxic reaction of Semen Pruni Armeniacae [13, 14, 17], and allergic response of Gypsum [37]. Recent reports indicated that Ephedrae decreased the acute toxicology of Semen Pruni Armeniacae, and licorice decreased acute toxicology of Ephedrae when these herb pairs are cotreated $[9,38]$. Therefore, we found that MXGST extract has a higher safe therapeutic index because the ephedrine and amygdalin levels in the MXGST extract for the antitussive and anti-pyretic tests are approximately 24-60 $\mu \mathrm{g}$ ephedrine/g body weight and 176-440 $\mu \mathrm{g}$ amygdalin/g body weight (thousandth of $\mathrm{LD}_{50}$ dose of ephedrine and amygdalin).

\section{Conclusion}

Based on our present results, MXGST extract is a very safe Chinese prescription that possesses pronounced antitussive and anti-pyretic activities, confirming its clinical utility for cough, bronchial inflammation and fever caused from pneumonia. The antitussive mechanism of MXGST might be related to dilating the bronchial smooth muscle by inhibiting histaminergic and acetylcholinergic receptors in the bronchial tract, activating both sympathomimetic $\alpha$ - and $\beta$-adrenergic
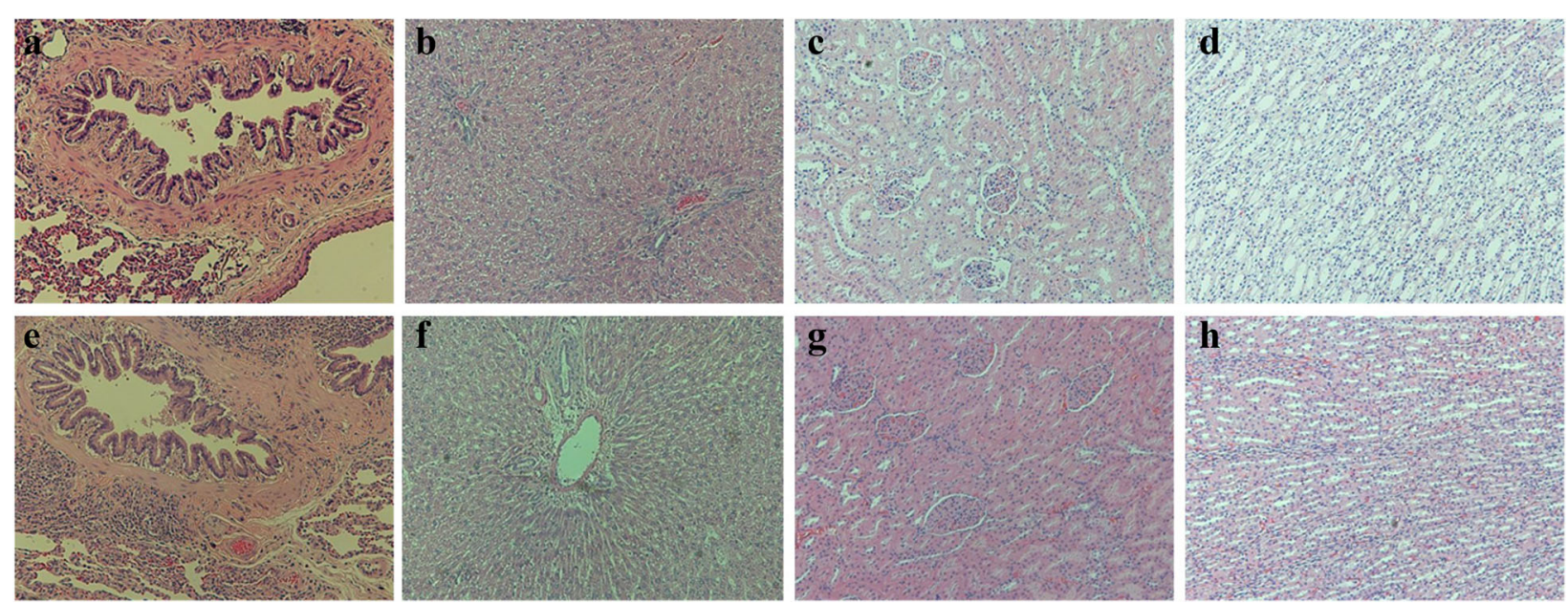

Fig. 5 Histology of lung, liver and kidney (H\&E, 100x) in rats. (a), (c), (e) and (i) Section of lung, liver and kidney from vehicle-treated rats; (b), (d), (f) and (j) Section of liver and kidney from Ma-Xing-Gan-Shi-Tang (MXGST, $2.0 \mathrm{~g} / \mathrm{kg}$, po)-treated rats 


\section{receptors from ephedra alkaloids and inhibiting central cough center from amygdalin.}

\section{Abbreviations}

ALT: Alanine transaminase; AST: Aspartate transaminase; BUN: Blood urea nitrogen; HCT: Hematocrit; HGB: Hemoglobin; LPS: Lipopolysaccharides; MCH: Mean corpuscular hemoglobin; MCHC: Mean corpuscular hemoglobin concentration; MCV: Mean corpuscular volume; MXGST: Ma-Xing-Gan-ShiTang; RBC: Red blood cells; WBC: White blood cells

\section{Acknowledgments}

We thank the financial support of Ministry of Health and Welfare CCMP98CP-010, CCMP99-CP-010 and CCMP100-CP-010.

\section{Availability of data and materials}

The datasets supporting the conclusions of this article are included within this article.

\section{Authors' contributions}

CRW carried out all the experimentation, acquisition of data, conceived, designed and supervised the study. The manuscript was also drafted and revised by CRW. YCL and CWC provided the plant extracts. All authors read and approved the final manuscript.

\section{Competing interests}

The authors declare that they have no competing interests.

\section{Consent for publication}

This information is not relevant.

\section{Ethics approval}

The experimental protocol (Protocol No. 102-103-NH) was approved by the Institutional Animal Care and Use Committee (IACUC) of China Medical University and the care of animal was carried out according to the Guiding Principles for the Care and Use of Laboratory Animals.

\section{Author details}

'Department of Medicinal Botanicals and Health Applications, DaYeh University, No.168, University Road, Dacun, Changhua 51591, Taiwan, ROC ${ }^{2}$ Department of Cosmetic Applications and Management, Mackay Junior College of Medicine, Nursing and Management, No. 92, Shengjing Road, Beitou District, Taipei 11260, Taiwan, ROC. ${ }^{3}$ Department of Chinese Pharmaceutical Sciences and Chinese Medicine Resources, China Medical University, No. 91, Hsieh Shih Road, Taichung 40402, Taiwan, ROC

\section{Received: 10 June 2016 Accepted: 27 October 2016}

Published online: 10 November 2016

\section{References}

1. Fuller R, Hansson L, Karlsson JA. Neurophysiology of the cough reflex. Eur Respir J. 1996;9(3):622-4.

2. Canning BJ. Anatomy and neurophysiology of the cough reflex: ACCP evidence-based clinical practice guidelines. Chest. 2006;129(1 Suppl):33S-47S.

3. Grattan TJ, Marshall AE, Higgins KS, Morice AH. The effect of inhaled and oral dextromethorphan on citric acid induced cough in man. Br J Clin Pharmacol. 1995;39(3):261-3.

4. Balbani AP. Cough: neurophysiology, methods of research, pharmacological therapy and phonoaudiology. Int Arch Otorhinolaryngol. 2012;16(2):259-68.

5. Ma C. Application thought and mechanism of Ma-Xing-Gan-Shi-Tang. Jiangsu J Tradit Chin Med. 2011;43(6):66-8.

6. Zhang ZH, Wang SC, Wang RJ, Wu SH, Wang CH, Hu YW. Influence on rabbit fever model and antiviral action of two kinds of Ma-Xing-Shi-Gan decotum extract. J Fourth Milti Med Univ. 1997;18(6):522-4.

7. Yeh ZJ, Kao ST, Yeh FC, Lin JG. Effects of Ma-Xing-Gan-Shi-Tang on the respiratory resistence and inflammatory cells in allergy-induced asthma guinea pigs. J Anhui TCM Coll. 1998;17(1):51-5.

8. Cui YR, Qu F, Xu J, Xu GL. Research of dose-effect relationship of Maxin Shigan Decoction with the dosage changes of Gypsum Fibrosurn. Chin J Exp Tradit Med Form. 2013;19(23):187-92.
9. Tan XM, Guo Y, Yu LZ, Zhuo HF, Luo JB. Effect of Ephedra with Semen Armeniacae Amarum by compatibility of different ratio in acute toxicity test and antiasthmatic. Pharmacol Clin Chin Mater Med. 2013;29(1):82-4.

10. Huang $F$, Tong $X Y$, Zhang $R H$, Cai $Y$. Primary study on the mechanism of Ma-Xing-Shi-Gan decoction on the Th1/Th2 response in a murine model of asthma. J Chin Med Mater. 2008;31(10):1519-22.

11. Hollister AS, Kearns GL. American Society for Clinical Pharmacology and Therapeutics position statement on the public health risks of ephedra. Clin Pharmacol Ther. 2003;74(5):403-5.

12. Abourashed EA, El-Alfy AT, Khan IA, Walker L. Ephedra in perspective-a current review. Phytother Res. 2003:17(7):703-12.

13. Moertel CG, Ames MM, Kovach JS, Moyer TP, Rubin JR, Tinker JH. A pharmacologic and toxicological study of amygdalin. JAMA. 1981;245(6):591-4

14. Newton GW, Schmidt ES, Lewis JP, Conn E, Lawrence R. Amygdalin toxicity studies in rats predict chronic cyanide poisoning in humans. West J Med. 1981;134(2):97-103.

15. Forsberg K, Karlsson JA, Zackrisson C, Persson CG. Selective inhibition of cough and bronchoconstriction in conscious guinea pigs. Respiration. 1992:59(2):72-6.

16. Kassuya CA, Cremoneze A, Barros LF, Simas AS, Lapa Fda R, Mello-Silva R, Stefanello ME, Zampronio AR. Antipyretic and anti-inflammatory properties of the ethanolic extract, dichloromethane fraction and costunolide from Magnolia ovata (Magnoliaceae). J Ethnopharmacol. 2009;124(3):369-76.

17. Khandekar JD. Amygdalin (laetrile) toxicity in rodents. JAMA. 1980;243(23):2396.

18. Blechman KM, Karch SB, Stephens BG. Demographic, pathologic, and toxicological profiles of 127 decedents testing positive for ephedrine alkaloids. Forensic Sci Int. 2004;139(1):61-9.

19. Ray S, Phadke S, Patel C, Hackman RM, Stohs S. Short-term and long-term in vivo exposure to an ephedra- and caffeine-containing metabolic nutrition system does not induce cardiotoxicity in B6C3F1 mice. Arch Toxicol. 2005:79(6):330-40.

20. Kao TC, Wu CH, Yen GC. Bioactivity and potential health benefits of licorice. J Agric Food Chem. 2014;62(3):542-53.

21. OECD. Test No. 407: repeated Dose 28-day oral toxicity study in rodents. In: OECD guidelines for the testing of chemicals, Section 4: Health Effects. Paris: OECD Publishing; 2008.

22. Wintrobe MM. Clinical Haemotology. Philadelphia: Lea and Febigeer; 1961

23. Li TM, Deng MZ. Antitussive, anti-inflammatory and analgesic effects of MaXingShiGan decoction on rats with acute pharyngitis. J ShanXi Coll Tradit Chin Med. 2012;13(3):019.

24. Minamizawa K, Goto H, Shimada Y, Terasawa K, Haji A. Effects of eppikahangeto, a Kampo formula, and Ephedrae herba against citric acidinduced laryngeal cough in guinea pigs. J Pharmacol Sci. 2006;101(2):118-25.

25. Miyagoshi M, Amagaya S, Ogihara Y. Antitussive effects of L-ephedrine, amygdalin, and makyokansekito (Chinese traditional medicine) using a cough model induced by sulfur dioxide gas in mice. Planta Med. 1986;4:275-8.

26. Yuizono T. On the site of antitussive actions of ethyldibunate, benzonatate and (--)-methylephedrine. Yakugaku Zasshi. 1967:87(8):923-34

27. Hiralal Ghante M, Bhusari KP, Duragkar NJ, Ghiware NB. Pharmacological evaluation for anti-asthmatic and anti-inflammatory potential of Woodfordia fruticosa flower extracts. Pharm Biol. 2014;52(7):804-13.

28. Kamei J, Saitoh A, Asano T, Nakamura R, Ichiki H, liduka A, Kubo M. Pharmacokinetic and pharmacodynamic profiles of the antitussive principles of Glycyrrhizae radix (licorice), a main component of the Kampo preparation Bakumondo-to (Mai-men-dong-tang). Eur J Pharmacol. 2005;507(1-3):163-8.

29. Mutolo D, Bongianni F, Cinelli E, Pantaleo $T$. Role of excitatory amino acids in the mediation of tracheobronchial cough induced by citric acid inhalation in the rabbit. Brain Res Bull. 2009:80(1-2):22-9.

30. Leung SY, Niimi A, Williams AS, Nath P, Blanc FX, Dinh QT, Chung KF. Inhibition of citric acid- and capsaicin-induced cough by novel TRPV- 1 antagonist, V112220, in guinea-pig. Cough. 2007;3:10.

31. Tanaka M, Maruyama K. Mechanisms of capsaicin- and citric-acid-induced cough reflexes in guinea pigs. J Pharmacol Sci. 2005:99(1):77-82.

32. El-Hashim AZ, Wyss D, Lewis C. Effect of a novel NK1 receptor selective antagonist (NKP608) on citric acid induced cough and airway obstruction. Pulm Pharmacol Ther. 2004;17(1):11-8.

33. Daoui S, Cognon C, Naline E, Emonds-Alt X, Advenier C. Involvement of tachykinin NK3 receptors in citric acid-induced cough and bronchia responses in guinea pigs. Am J Respir Crit Care Med. 1998;158(1):42-8.

34. Zhou YX, Lin M, Tang ZS, Wang B, Zhang B. An study on gypsum compounds and their antipyretic function and anti-inflammatory mechanisms. J ShaanXi Coll Tradit Chin Med. 2012;35(5):033. 
35. Saxene RC, Bhalla TN. Antipyretic effect of glycyrrhetic acid and imipramine. Jpn J Pharmacol. 1968;18(3):353-5.

36. Mei F, Xing XF, Tang QF, Chen FL, Guo Y, Song S, Tan XM, Luo JB. Antipyretic and anti-asthmatic activities of traditional Chinese herb-pairs, Ephedra and Gypsum. Chin J Integr Med. 2014;22(6):445-50.

37. Szczeklik A, Adamek T, Owsinski J, Czerniawska-Mysik G, Musial J. Allergic reactions to gypsum. Pol Tyg Lek. 1975;30(5):205-6.

38. Zhao J, Yu LZ, Fang F, Xu WJ, Lu JB. Quantitative evaluation of acute toxicity of Ephedra sinica -Glycyrrhiza uralensis medicine pair. Pharmacol Clin Chin Mater Med. 2012;28(4):15-8.

Submit your next manuscript to BioMed Central and we will help you at every step:

- We accept pre-submission inquiries

- Our selector tool helps you to find the most relevant journal

- We provide round the clock customer support

- Convenient online submission

- Thorough peer review

- Inclusion in PubMed and all major indexing services

- Maximum visibility for your research

Submit your manuscript at www.biomedcentral.com/submit
Biomed Central 